\title{
Propeller-Shaped ZnO Nanostructures Obtained by Chemical Vapor Deposition: Photoluminescence and Photocatalytic Properties
}

\author{
S. L. Wang, ${ }^{1}$ H. W. Zhu, ${ }^{1}$ W. H. Tang, ${ }^{2}$ and P. G. Li ${ }^{1}$ \\ ${ }^{1}$ Department of Physics, Zhejiang Sci-Tech University, Hangzhou 310018, China \\ ${ }^{2}$ School of Science, Beijing University of Posts and Telecommunications, Beijing 100876, China \\ Correspondence should be addressed to S. L. Wang, slwang@zstu.edu.cn and P. G. Li, pgli@zstu.edu.cn
}

Received 30 September 2011; Revised 16 November 2011; Accepted 25 November 2011

Academic Editor: Laécio Santos Cavalcante

Copyright () 2012 S. L. Wang et al. This is an open access article distributed under the Creative Commons Attribution License, which permits unrestricted use, distribution, and reproduction in any medium, provided the original work is properly cited.

Propeller-shaped and flower-shaped $\mathrm{ZnO}$ nanostructures on Si substrates were prepared by a one-step chemical vapor deposition technique. The propeller-shaped $\mathrm{ZnO}$ nanostructure consists of a set of axial nanorod $(50 \mathrm{~nm}$ in tip, $80 \mathrm{~nm}$ in root and $1 \mu \mathrm{m}$ in length), surrounded by radial-oriented nanoribbons $(20-30 \mathrm{~nm}$ in thickness and $1.5 \mu \mathrm{m}$ in length). The morphology of flowershaped $\mathrm{ZnO}$ nanostructure is similar to that of propeller-shaped $\mathrm{ZnO}$, except the shape of leaves. These nanorods leaves $(30 \mathrm{~nm}$ in diameter and $1-1.5 \mu \mathrm{m}$ in length) are aligned in a radial way and pointed toward a common center. The flower-shaped $\mathrm{ZnO}$ nanostructures show sharper and stronger UV emission at $378 \mathrm{~nm}$ than the propeller-shaped $\mathrm{ZnO}$, indicating a better crystal quality and fewer structural defects in flower-shaped $\mathrm{ZnO}$. In comparison with flower-shaped $\mathrm{ZnO}$ nanostructures, the propellershaped $\mathrm{ZnO}$ nanostructures exhibited a higher photocatalytic property for the photocatalytic degradation of Rhodamine B under UV-light illumination.

\section{Introduction}

Zinc oxide $(\mathrm{ZnO})$, a remarkable II-VI semiconductor with a wide direct band gap of $3.37 \mathrm{eV}$ and large exciton binding energy of $60 \mathrm{meV}$ at room temperature, has attracted considerable interests due to potential application in photocatalysis [1], sensors [2], light-emitting diodes [3], solar cells [4], and so forth. Compared with $\mathrm{TiO}_{2}, \mathrm{ZnO}$ as a potential photocatalyst has the advantage of lower cost, absorbing more light quanta and higher photocatalytic efficiencies for the degradation of several organic pollutants in both acidic and basic medium than $\mathrm{TiO}_{2}[5,6]$. Many strategies have been developed to improve the photocatalytic activity of $\mathrm{ZnO}$ nanostructures such as changing the structural and morphological characters (size, shape, and crystalline structure, etc.) $[7,8]$. A variety of $\mathrm{ZnO}$ nanostructures such as nanowires [9], nanorings [10], nanorods [11], nanobelts [12], nanosheets [13], and star-shaped nanostructures [14] have been synthesized by a number of techniques, which mainly include the hydrothermal synthesis [15], solutionbased synthesis [16], template-based synthesis [17], chemical vapor deposition (CVD) [18], arc discharge technique [19], and thermal evaporation process [20]. Although many works have been reported about the $\mathrm{ZnO}$ nanostructures, little information concerning the photocatalytic activity of propeller-shaped $\mathrm{ZnO}$ nanostructures was presented in previous studies $[21,22]$.

In this letter, propeller-shaped and flower-shaped $\mathrm{ZnO}$ nanostructures were prepared on Si substrates by a one-step chemical vapor deposition technique. The morphology, crystal structure, optical property, and photocatalytic property were studied.

\section{Experimental Section}

2.1. Sample Preparation. N type Si (001) substrates $(1.5 \mathrm{~cm} \times$ $1.5 \mathrm{~cm}$ ) were ultrasonically cleaned in hydrochloric acid solution, acetone, and deionized water for $30 \mathrm{~min}$, respectively. Commercial $\mathrm{Zn}$ powder $(1.0 \mathrm{~g})$ with a purity of $99.999 \%$ was used as the source material and put in an alumina boat, two pieces of Si substrates (position1: near the $\mathrm{Zn}$ powder at a 
distance of $3 \mathrm{~cm}$, the sample was labeled as S1; position 2: far from the $\mathrm{Zn}$ powder at a distance of $5 \mathrm{~cm}$, the sample was labeled S2) were placed sequentially in the alumina boat. The boat was loaded into a furnace with a horizontal alumina tube. Two ends of the tube were sealed using mechanically clamped steel plates with the rubber gaskets. The tube was evacuated by a mechanical rotary pump. Then the furnace temperature was raised to $1000^{\circ} \mathrm{C}$ at a rate of $\sim 20^{\circ} \mathrm{C} / \mathrm{min}$ while oxygen gas was introduced into the chamber. After reaction for $1 \mathrm{~h}$, the furnace was cooled down to room temperature naturally.

2.2. Characterization. The crystallographic information of the prepared samples was analyzed by powder X-ray diffraction (XRD) using a Bruker AXS D8 DISCOVER X-ray diffractometer with $\mathrm{Cu} \operatorname{K} \alpha$ radiation $(\lambda=1.5406 \AA)$. The morphology and composition of the as-deposited products were characterized by field emission scanning electron microscope (FESEM, S-4800) and energy-dispersive X-ray spectrometry (EDX), respectively. Transmission electron microscopy (TEM) and high-resolution transmission electron microscopy (HRTEM) were performed on JEOL 2010F high-resolution TEM system. Photoluminescence properties of $\mathrm{ZnO}$ nanostructures were measured on a FLSP920 fluorescence spectrometer using a Xe lamp with the excitation wavelength of $320 \mathrm{~nm}$ at room temperature. BrunauerEmmett-Teller (BET) nitrogen adsorption-desorption was measured using a Micromeritics ASAP 2010 system.

The photocatalytic activity of the prepared samples was evaluated by the photocatalytic degradation of $\mathrm{RhB}$ aqueous solution performed at room temperature $\left(\mathrm{ca} .20^{\circ} \mathrm{C}\right)$. The experimental procedure was as follows. $0.01 \mathrm{~g}$ of the prepared powders was dispersed in $30 \mathrm{~mL}$ of $\mathrm{RhB}$ aqueous solution with a concentration of $1.0 \times 10^{-5} \mathrm{~mol} \cdot \mathrm{L}^{-1}$ in a beaker (with a capacity of $50 \mathrm{~mL}$ ), and the suspensions were placed in dark for $30 \mathrm{~min}$ before illumination to allow sufficient adsorption of RhB. A $100 \mathrm{~W}$ mercury lamp placed $2 \mathrm{~cm}$ above the beaker with a wavelength of $365 \mathrm{~nm}$ was used as a light source. The concentration of RhB aqueous solution was determined by a UV-visible spectrophotometer (UV-4802H, UNICO). After UV-light irradiation for $30 \mathrm{~min}$, the reaction solution was filtered, and then the absorbance of RhB aqueous solution was measured.

\section{Results and Discussion}

XRD analysis was adopted to analyze the crystal structure and phase composition of the obtained products. Figures $1(\mathrm{a}, \mathrm{b})$ show the XRD patterns of the products obtained at different position. All the diffraction peaks can be indexed to wurtzite hexagonal ZnO (JCPDS Card file no. 70-2551). No other diffraction peaks are detected, indicating that all the as-prepared products are pure $\mathrm{ZnO}$. Figure 2 shows FESEM images of the products obtained at different positions. As shown in Figure 2(a), the morphology of sample S1 is similar to the propellers, which consists of a set of axial nanorod ( $50 \mathrm{~nm}$ in tip, $80 \mathrm{~nm}$ in root and $1 \mu \mathrm{m}$ in length), surrounded by radial oriented nanoribbons $(20-30 \mathrm{~nm}$ in thickness and

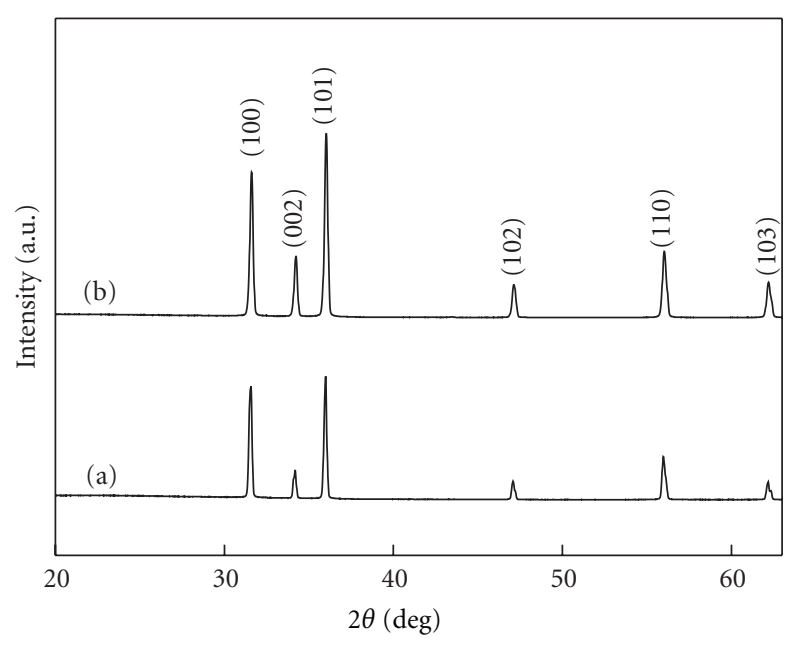

FIGURE 1: XRD patterns of the products obtained at different positions: (a) S1 and (b) S2.

$1.5 \mu \mathrm{m}$ in length). Figure 2(b) shows FESEM image of sample S2. The flower-shaped products are composed of aligned nanorods ( $30 \mathrm{~nm}$ in diameter and $1-1.5 \mu \mathrm{m}$ in length) in a radial way, and all the nanorods pointed toward a common center. BET surface area measurements of samples indicate that the $\mathrm{S}_{\mathrm{BET}}$ of propeller-shaped and flower-shaped $\mathrm{ZnO}$ nanostructures are $23.5 \mathrm{~m}^{2} / \mathrm{g}$ and $25.1 \mathrm{~m}^{2} / \mathrm{g}$, respectively.

TEM, HRTEM, and EDX were also used to characterize the structural properties of $\mathrm{ZnO}$ nanostructures. Figure 3(a) shows TEM image of a single nanoribbon in propellershaped $\mathrm{ZnO}$ nanostructures. The corresponding HRTEM image recorded from an individual nanoribbon (Figure 3(b)) clearly shows the well-resolved interference lattice fringe of about $0.28 \mathrm{~nm}$ that corresponds to the (100) crystal plane of $\mathrm{ZnO}$ phase. The EDX spectrum of propeller-shaped $\mathrm{ZnO}$ nanostructures was presented in Figure 3(c), in which the propeller-shaped products are composed only of $\mathrm{Zn}$ and $\mathrm{O}$, and this result is in good accordance with the XRD analysis. The appearance of Si peak in the spectrum attributes to the silicon substrate. Figures 3(d), 3(e), and 3(f) show the TEM image, HRTEM image, and EDX spectrum of flower-shaped $\mathrm{ZnO}$ nanostructures, respectively. All character results indicate that the products synthesized in both positions are $\mathrm{ZnO}$.

Figure 4 shows the room-temperature PL spectra recorded from propeller-shaped and flower-shaped $\mathrm{ZnO}$ nanostructures. The sharp peak at $378 \mathrm{~nm}$ corresponds to the near-band-edge emission (UV emission) of $\mathrm{ZnO}$, which is attributed to the recombination of photogenerated electrons and holes [23]. The peak at $495 \mathrm{~nm}$ corresponded to the deep-level emission (visible emission) is associated with defects in $\mathrm{ZnO}$ lattice, such as oxygen vacancy and $\mathrm{Zn}$ interstitials [23, 24]. The deep-level emission (Figure 4(a), propeller-shaped $\mathrm{ZnO}$ ) may indicate the existence of oxygen vacancies in the propeller-shaped nanostructures. Figure 4(b) shows a strong, dominated- and high-intensity peak at $378 \mathrm{~nm}$ in the UV region and a suppressed and weak band at $495 \mathrm{~nm}$ in the visible region. It is known 


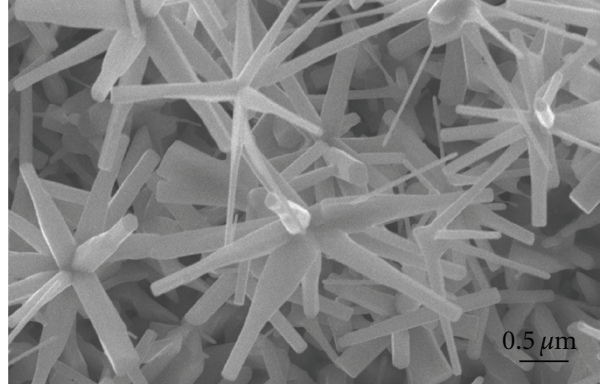

(a)

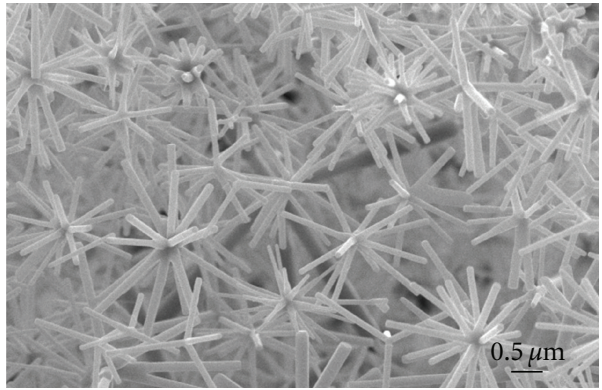

(b)

FIGURE 2: FESEM images of (a) propeller-shaped and (b) flower-shaped $\mathrm{ZnO}$ nanostructures.

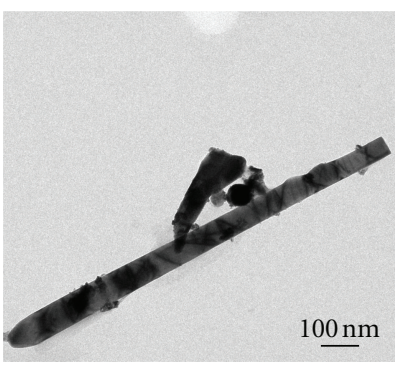

(a)

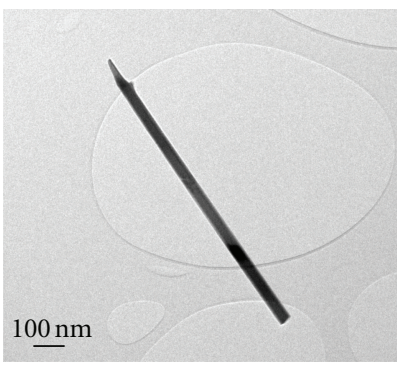

(d)

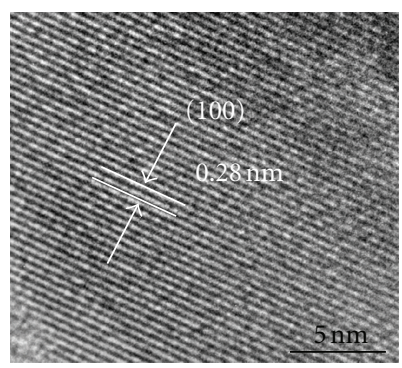

(b)

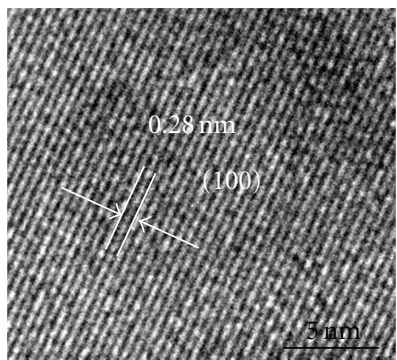

(e)

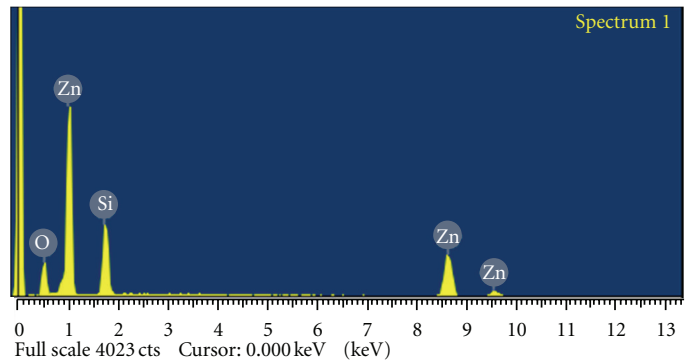

(c)

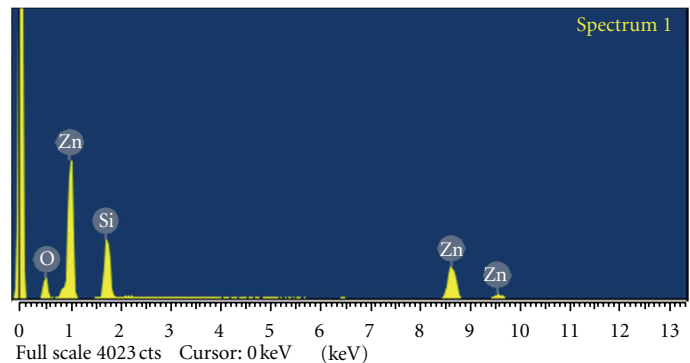

(f)

Figure 3: (a, b, and c) TEM image, HRTEM image, and EDX spectrum of the propeller-shaped ZnO nanostructures, respectively; (d, e, and f) TEM image, HRTEM image, and EDX spectrum of the flower-shaped $\mathrm{ZnO}$ nanostructures, respectively.

that the improvement in the crystal quality such as lowstructural defects, oxygen vacancies, zinc interstitials- and decrease in the impurities may cause the appearance of sharper and stronger UV emission and a suppressed and weakened green emission [25]. Thus, the strong UV emission and weak green emission observed in Figure 4(b) (flowershaped $\mathrm{ZnO}$ ) may be ascribed to the good crystal quality with less structural defects of flower-shaped $\mathrm{ZnO}$ nanostructures. The significant defect-related emission property of $\mathrm{ZnO}$ nanostructures may be beneficial to their photocatalytic property.

Heterogeneous semiconductor $\left(\mathrm{TiO}_{2}\right.$ and $\left.\mathrm{ZnO}\right)$ photocatalysis is a promising new alternative method among advanced oxidation processes (AOPs) which generally includes $\mathrm{UV} / \mathrm{H}_{2} \mathrm{O}_{2}, \mathrm{UV} / \mathrm{O}_{3}$ or $\mathrm{UV} /$ Fenton's reagent for oxidative removal of organic chemicals [26-28]. To demonstrate the photocatalytic of the $\mathrm{ZnO}$ nanostructures, the degradation of $\mathrm{RhB}$ was examined as a model reaction.
The variety of characteristic absorption of $\mathrm{RhB}$ at $554 \mathrm{~nm}$ was applied to monitor the photocatalytic degradation process. Figure 5 shows the UV-vis absorption spectrum of an aqueous solution of $\mathrm{RhB}$ (initial concentration: $1.0 \times$ $10^{-5} \mathrm{M}, 30 \mathrm{~mL}$ ) in the presence of propeller-shaped $\mathrm{ZnO}$ nanostructures $(0.01 \mathrm{~g})$ under UV irradiation. The absorption peaks corresponding to $\mathrm{RhB}$ diminished gradually as the exposure time was extended. Figure 6 shows the comparison of photocatalytic activities of propeller-shaped and flowershaped $\mathrm{ZnO}$ nanostructures. Significantly, the concentration of RhB barely changed without any catalyst (Figure 6(a)), whereas that of $\mathrm{RhB}$ gradually decreased in the presence of propeller-shaped and flower-shaped $\mathrm{ZnO}$ nanostructures under UV-light illumination. Obviously, the photocatalytic ability of propeller-shaped $\mathrm{ZnO}$ nanostructures is better than that of flower-shaped $\mathrm{ZnO}$ nanostructures (Figure 6(b, c)).

When the heterogeneous semiconductors are illuminated with UV-light, the electron/hole pairs are produced with 


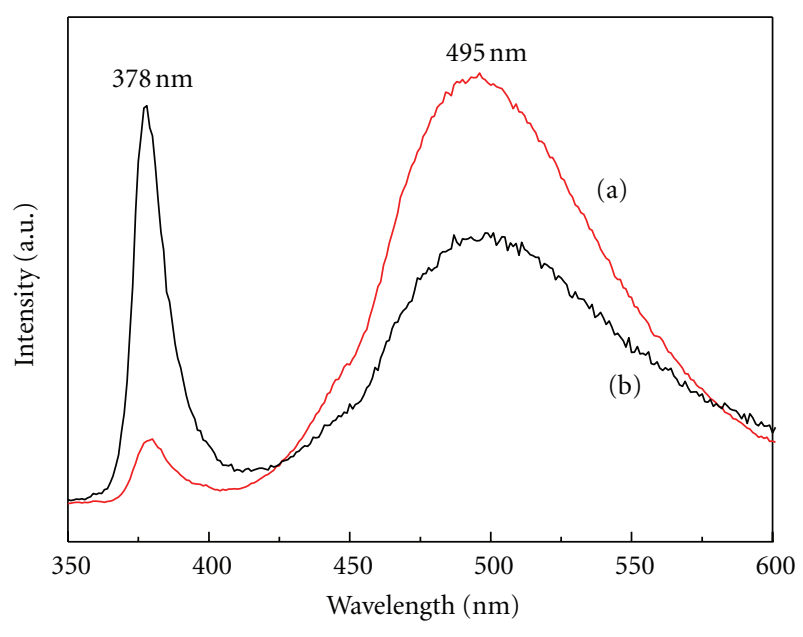

Figure 4: Photoluminescence spectra of (a) propeller-shaped and (b) flower-shaped $\mathrm{ZnO}$ nanostructures.

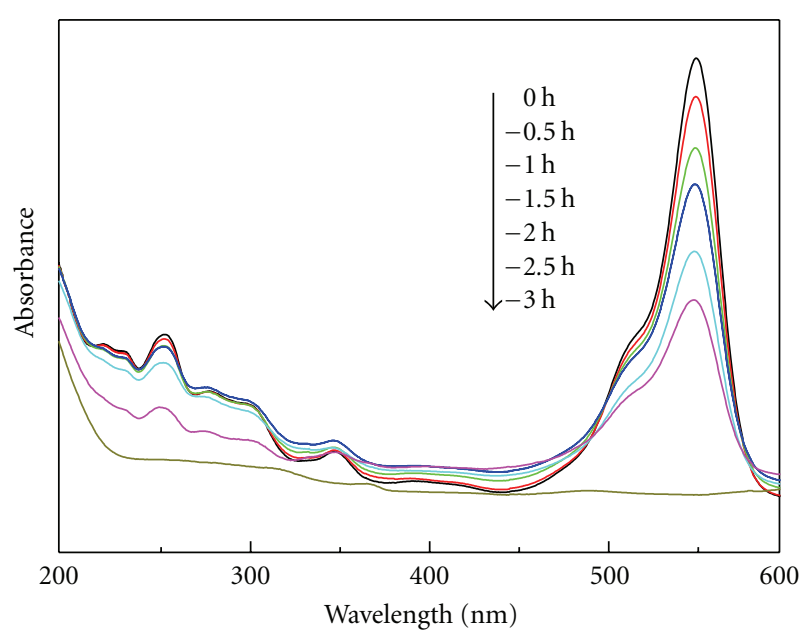

FIGURE 5: Absorption spectrum of the RhB solution in the presence of propeller-shaped $\mathrm{ZnO}$ nanostructures.

electrons promoted to the conduction band and leaving the positive holes in the valence band. These electron hole pairs can either recombine or can interact separately with other molecules and induce a complex series of reactions that might result in the complete degradation of the dye pollutants adsorbed on the surface of the semiconductor materials [29-31]. Based on the PL results mentioned above, the peak at $378 \mathrm{~nm}$ is due to the recombination of a photogenerated hole with an electron occupying the oxygen vacancies in the $\mathrm{ZnO}$ nanostructures, whereas the peak at $495 \mathrm{~nm}$ is caused by the recombination of electrons in single-occupied oxygen vacancies [31]. The low PL spectrum intensity at $378 \mathrm{~nm}$ (Figure 4(a), propeller-shaped $\mathrm{ZnO}$ ) indicates that the rate of the recombination between photogenerated holes and electrons might be lower on the surface of propeller-shaped $\mathrm{ZnO}$ nanostructures than that of flower-shaped $\mathrm{ZnO}$ nanostructures, which is beneficial for the photocatalytic reaction. The PL spectra at $495 \mathrm{~nm}$ show that oxygen vacancies might

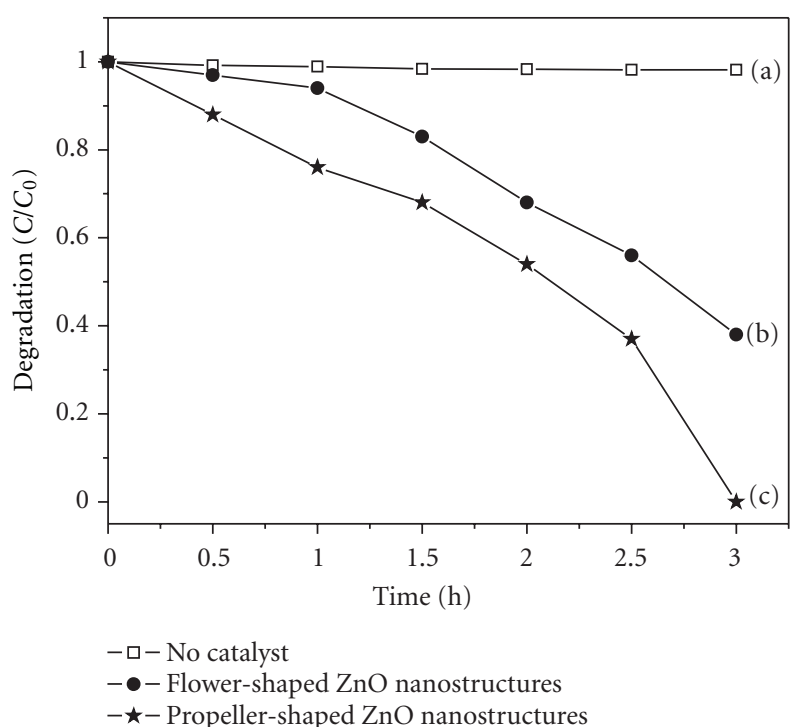

FIgure 6: Photodegradation of RhB $\left(1.0 \times 10^{-5} \mathrm{M}, 30 \mathrm{~mL}\right)$ under UV-light: (a) no catalyst, (b) flower-shaped $\mathrm{ZnO}$ nanostructures, and (c) propeller-shaped $\mathrm{ZnO}$ nanostructures. $\mathrm{C}$ is the concentration of $\mathrm{RhB}$, and $\mathrm{C}_{0}$ is the initial concentration.

be presented in both the propeller-shaped and flower-shaped $\mathrm{ZnO}$ nanostructures. Considering the $\mathrm{S}_{\mathrm{BET}}$ of propellershaped samples $\left(23.5 \mathrm{~m}^{2} / \mathrm{g}\right)$ is lower than that of the flowershaped ones $\left(25.1 \mathrm{~m}^{2} / \mathrm{g}\right)$, the higher photocatalytic property of propeller-shaped $\mathrm{ZnO}$ nanostructures for the degradation of $\mathrm{RhB}$ molecules may be caused by the lower rate of recombination between photogenerated holes and electrons on the surface of propeller-shaped $\mathrm{ZnO}$ nanostructures.

\section{Conclusions}

Propeller-shaped and flower-shaped $\mathrm{ZnO}$ nanostructures were prepared on $\mathrm{Si}$ substrates by chemical vapor deposition technique. In comparison with the propeller-shaped $\mathrm{ZnO}$, the flower-shaped $\mathrm{ZnO}$ nanostructures show sharper and stronger UV emission at $378 \mathrm{~nm}$ and broader and weaker green emission at $495 \mathrm{~nm}$, indicating a better crystal quality and fewer structural defects in the flower-shaped $\mathrm{ZnO}$. However, the propeller-shaped $\mathrm{ZnO}$ nanostructures exhibited a more effective photocatalytic property for the photocatalytic degradation of Rhodamine B under UV-light illumination than flower-shaped $\mathrm{ZnO}$ nanostructures.

\section{Acknowledgments}

This work was supported by the National Basic Research Program of China (973 Program) (Grant no. 2010CB933501), the National Natural Science Foundation of China (Grant no. 51072182, 60806045 and 51172208), and the Natural Science Foundation of Zhejiang Province (Grant no. Y1110519). 


\section{References}

[1] T. J. Kuo, C. N. Lin, C. L. Kuo, and M. H. Huang, "Growth of ultralong $\mathrm{ZnO}$ nanowires on silicon substrates by vapor transport and their use as recyclable photocatalysts," Chemistry of Materials, vol. 19, no. 21, pp. 5143-5147, 2007.

[2] X. Wang, J. Zhou, J. Song, J. Liu, N. Xu, and Z. L. Wang, "Piezoelectric field effect transistor and nanoforce sensor based on a single ZnO nanowire," Nano Letters, vol. 6, no. 12, pp. 2768-2772, 2006.

[3] K. Keem, D. Y. Jeong, S. Kim et al., "Fabrication and device characterization of omega-shaped-gate $\mathrm{ZnO}$ nanowire fieldeffect transistors," Nano Letters, vol. 6, no. 7, pp. 1454-1458, 2006.

[4] T. P. Chou, Q. Zhang, G. E. Fryxell, and G. Cao, "Hierarchically structured $\mathrm{ZnO}$ film for dye-sensitized solar cells with enhanced energy conversion efficiency," Advanced Materials, vol. 19, no. 18, pp. 2588-2592, 2007.

[5] L. Y. Yang, S. Y. Dong, J. H. Sun, J. L. Feng, Q. H. Wu, and S. P. Sun, "Microwave-assisted preparation, characterization and photocatalytic properties of a dumbbell-shaped $\mathrm{ZnO}$ photocatalyst," Journal of Hazardous Materials, vol. 179, no. 13, pp. 438-443, 2010.

[6] J. C. Lee, S. Park, H. J. Park, J. H. Lee, H. S. Kim, and Y. J. Chung, "Photocatalytic degradation of TOC from aqueous phenol solution using solution combusted $\mathrm{ZnO}$ nanopowders," Journal of Electroceramics, vol. 22, no. 1-3, pp. 110-113, 2009.

[7] Y. Zhang, W. Zhang, and H. Zheng, "Fabrication and photoluminescence properties of $\mathrm{ZnO}: \mathrm{Zn}$ hollow microspheres," Scripta Materialia, vol. 57, no. 4, pp. 313-316, 2007.

[8] M. S. Mohajerani, M. Mazloumi, A. Lak, A. Kajbafvala, S. Zanganeh, and S. K. Sadrnezhaad, "Self-assembled zinc oxide nanostructures via a rapid microwave-assisted route," Journal of Crystal Growth, vol. 310, no. 15, pp. 3621-3625, 2008.

[9] Y. C. Kong, D. P. Yu, B. Zhang, W. Fang, and S. Q. Feng, "Ultraviolet-emitting $\mathrm{ZnO}$ nanowires synthesized by a physical vapor deposition approach," Applied Physics Letters, vol. 78, no. 4, pp. 407-409, 2001.

[10] X. Y. Kong, Y. Ding, R. Yang, and Z. L. Wang, "Single-crystal nanorings formed by epitaxial self-coiling of polar nanobelts," Science, vol. 303, no. 5662, pp. 1348-1351, 2004.

[11] F. P. Albores, F. P. Delgado, W. A. Flores, P. A. Madrid, E. R. Valdovinos, and M. M. Yoshida, "Microstructural study of $\mathrm{ZnO}$ nano structures by rietveld analysis," Journal of Nanomaterials, vol. 2011, Article ID 643126, 11 pages, 2011.

[12] C. Ronning, P. X. Gao, Y. Ding, Z. L. Wang, and D. Schwen, "Manganese-doped $\mathrm{ZnO}$ nanobelts for spintronics," Applied Physics Letters, vol. 84, no. 5, pp. 783-785, 2004.

[13] R. C. Wang, C. P. Liu, J. L. Huang, and S. J. Chen, " $\mathrm{ZnO}$ symmetric nanosheets integrated with nanowalls," Applied Physics Letters, vol. 87, no. 5, Article ID 053103, 2005.

[14] A. Umar, S. Lee, Y. S. Lee, K. S. Nahm, and Y. B. Hahn, "Star-shaped $\mathrm{ZnO}$ nanostructures on silicon by cyclic feeding chemical vapor deposition," Journal of Crystal Growth, vol. 277, no. 1-4, pp. 479-484, 2005.

[15] G. Amin, M. H. Asif, A. Zainelabdin, S. Zaman, O. Nur, and $\mathrm{M}$. Willander, "Influence of $\mathrm{pH}$, precursor concentration, growth time, and temperature on the morphology of $\mathrm{ZnO}$ nanostructures grown by the hydrothermal method," Journal of Nanomaterials, vol. 2011, Article ID 269692, 9 pages, 2011.

[16] L. Poul, S. Ammar, N. Jouini, F. Fiévet, and F. Villain, "Metastable solid solutions in the system $\mathrm{ZnO}-\mathrm{CoO}$ : synthesis by hydrolysis in polyol medium and study of the morphological characteristics," Solid State Sciences, vol. 3, no. 1-2, pp. 31-42, 2001.

[17] X. Sun, J. Liu, and Y. Li, "Use of carbonaceous polysaccharide microspheres as templates for fabricating metal oxide hollow spheres," Chemistry-A European Journal, vol. 12, no. 7, pp. 2039-2047, 2006.

[18] Z. Fan, D. Wang, P. C. Chang, W. Y. Tseng, and J. G. Lu, "ZnO nanowire field-effect transistor and oxygen sensing property," Applied Physics Letters, vol. 85, no. 24, pp. 5923-5925, 2004.

[19] Y. C. Choi, W. S. Kim, Y. S. Park et al., "Catalytic growth of $\beta$ $\mathrm{Ga}_{2} \mathrm{O}_{3}$ nanowires by arc discharge," Advanced Materials, vol. 12, no. 10, pp. 746-750, 2000.

[20] D. Peng, Y. Huang, K. Yu, L. Li, and Z. Zhu, "Synthesis and field emission properties of hierarchical $\mathrm{ZnO}$ nanostructures," Journal of Nanomaterials, vol. 2010, Article ID 560409, 5 pages, 2010.

[21] J. Liu, X. Huang, Y. Li, Q. Zhong, and L. Ren, "Preparation and photoluminescence of $\mathrm{ZnO}$ complex structures with controlled morphology," Materials Letters, vol. 60, no. 11, pp. 1354-1359, 2006.

[22] Z. L. Wang, "Novel nanostructures of $\mathrm{ZnO}$ for nanoscale photonics, optoelectronics, piezoelectricity, and sensing," Applied Physics A, vol. 88, no. 1, pp. 7-15, 2007.

[23] L. Xu, Y. Guo, Q. Liao, J. Zhang, and D. Xu, "Morphological control of $\mathrm{ZnO}$ nanostructures by electrodeposition," Journal of Physical Chemistry B, vol. 109, no. 28, pp. 13519-13522, 2005.

[24] C. C. Lin, K. H. Liu, and S. Y. Chen, "Growth and characterization of $\mathrm{Zn}-\mathrm{ZnO}$ core-shell polygon prismatic nanocrystals on Si," Journal of Crystal Growth, vol. 269, no. 2-4, pp. 425-431, 2004.

[25] D. M. Bagnall, Y. F. Chen, Z. Zhu, T. Yao, M. Y. Shen, and T. Goto, "High temperature excitonic stimulated emission from ZnO epitaxial layers," Applied Physics Letters, vol. 73, no. 8, pp. 1038-1040, 1998.

[26] P. R. Gogate and A. B. Pandit, "A review of imperative technologies for wastewater treatment I: oxidation technologies at ambient conditions," Advances in Environmental Research, vol. 8, no. 3-4, pp. 501-551, 2004.

[27] P. R. Gogate and A. B. Pandit, "A review of imperative technologies for wastewater treatment II: hybrid methods," Advances in Environmental Research, vol. 8, no. 3-4, pp. 553597, 2004.

[28] E. Yassitepe, H. C. Yatmaz, C. Öztürk, K. Öztürk, and C. Duran, "Photocatalytic efficiency of $\mathrm{ZnO}$ plates in degradation of azo dye solutions," Journal of Photochemistry and Photobiology A, vol. 198, no. 1, pp. 1-6, 2008.

[29] H. Kyung, J. Lee, and W. Choi, "Simultaneous and synergistic conversion of dyes and heavy metal ions in aqueous $\mathrm{TiO}_{2}$ suspensions under visible-light illumination," Environmental Science and Technology, vol. 39, no. 7, pp. 2376-2382, 2005.

[30] B. Pal and M. Sharon, "Enhanced photocatalytic activity of highly porous $\mathrm{ZnO}$ thin films prepared by sol-gel process," Materials Chemistry and Physics, vol. 76, no. 1, pp. 82-87, 2002.

[31] J. H. Sun, S. Y. Dong, Y. K. Wang, and S. P. Sun, "Preparation and photocatalytic property of a novel dumbbell-shaped $\mathrm{ZnO}$ microcrystal photocatalyst," Journal of Hazardous Materials, vol. 172, no. 2-3, pp. 1520-1526, 2009. 

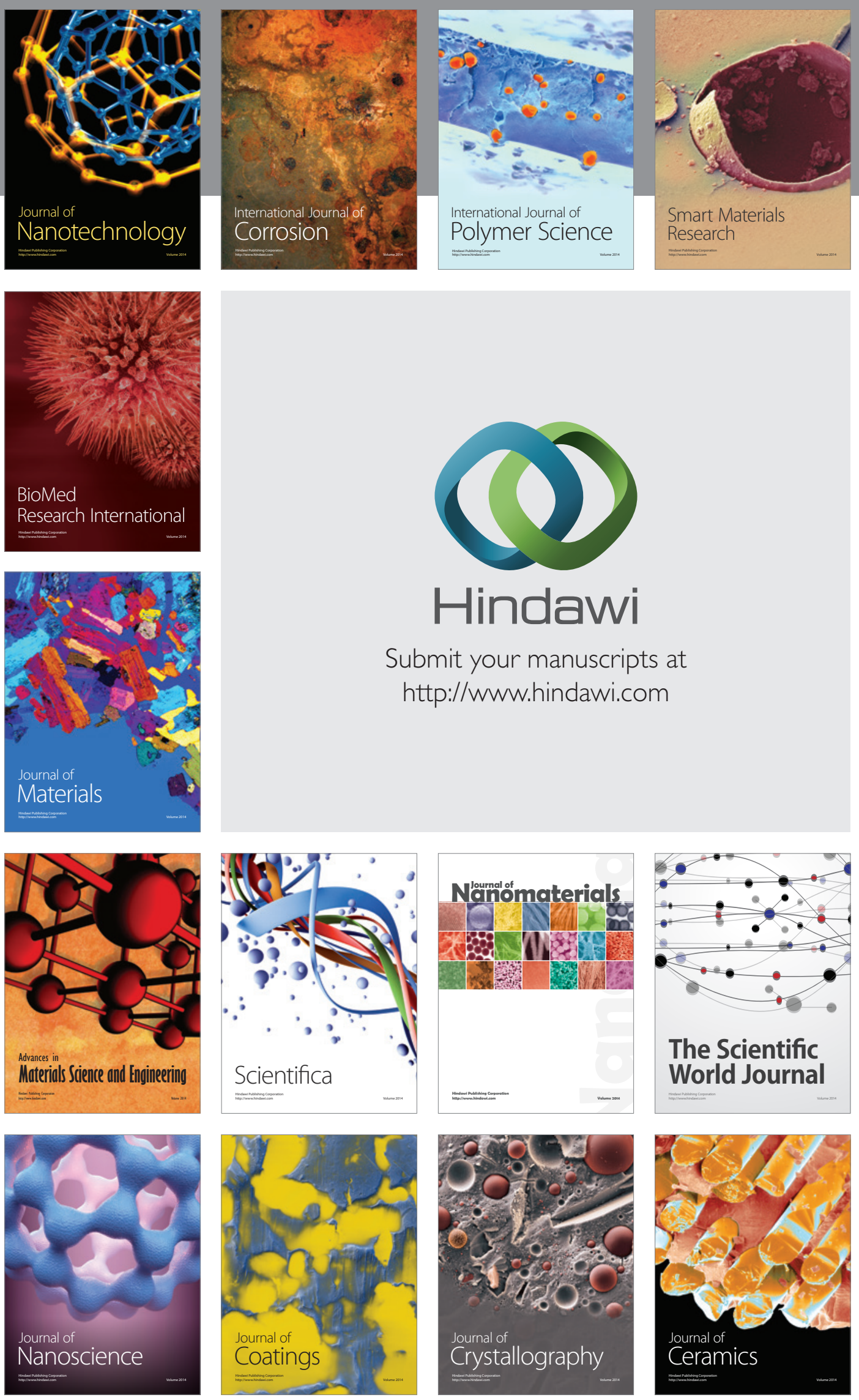

The Scientific World Journal

Submit your manuscripts at

http://www.hindawi.com

\section{World Journal}

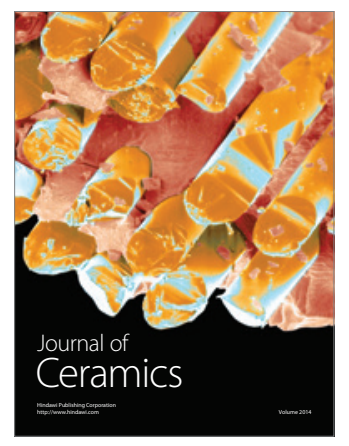

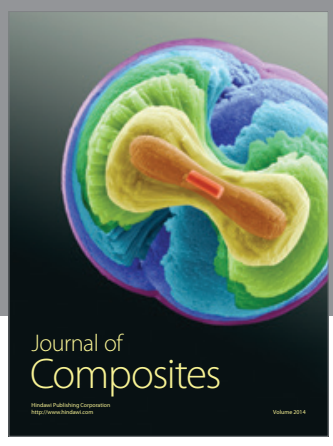
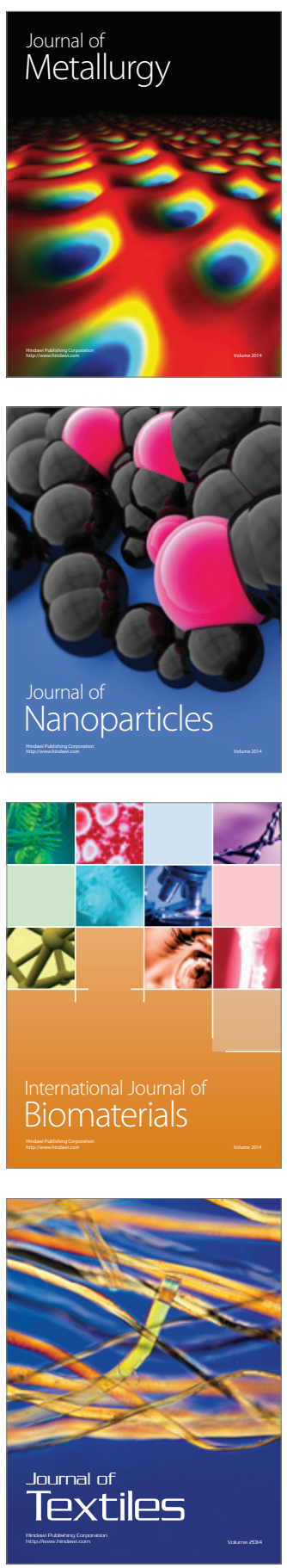